\title{
Nursing diagnoses, results, and interventions in the care for Covid-19 patients in critical condition
}

\author{
Diagnósticos, resultados e intervenções de enfermagem no \\ cuidado a pessoas com Covid-19 em estado crítico \\ Diagnósticos, resultados e intervenciones de enfermería en el \\ cuidado a personas con Covid-19 en estado crítico
}

How to cite this article:

Menezes HF, Moura JL, Oliveira SS, Fonseca MC, Sousa PAF, Silva RAR. Nursing diagnoses, results, and interventions in the care for Covid-19 patients in critical condition. Rev Esc Enferm USP. 2021;55:e20200499. doi: https://doi.org/10.1590/1980-220X-REEUSP-2020-0499.

\section{Harlon França de Menezes ${ }^{1}$ \\ Jéssica Lima Moura² \\ Sylvia Silva de Oliveira ${ }^{2}$ \\ iD Michelle Carneiro Fonseca² \\ D Paulino Artur Ferreira de Sousa ${ }^{3}$ \\ Richardson Augusto Rosendo da Silva ${ }^{2}$}

${ }^{1}$ Universidade Federal Fluminense, Escola de Enfermagem Aurora de Afonso Costa, Niterói, RJ, Brazil.

${ }^{2}$ Universidade Federal do Rio Grande do Norte, Natal, RN, Brazil

${ }^{3}$ Escola Superior de Enfermagem do Porto, Porto, Portugal.

\section{ABSTRACT}

Objective: To develop and validate a terminological subset of the International Classification for Nursing Practice for COVID-19 patients in critical care. Method: This is a methodological study, which followed the guidelines of the Brazilian method using the Basic Human Needs as a theoretical model. Content validation was performed by 25 specialist nurses using the Delphi technique. Results: A total of 73 diagnoses and their respective nursing results were prepared. Of these, 62 statements had a Content Validity Index $\geq 0.80$, with the need for oxygenation having the highest number of statements. Of the 210 nursing interventions developed, and after suggestions from experts, 150 interventions reached an index $\geq 0.80$ and comprised the terminological subset. Conclusion: The terminological subset developed showed statements that were validated by specialist nurses and, therefore, are relevant to the nurse's clinic in the critical care scenario associated with Covid-19.

\section{DESCRIPTORS}

Coronavirus Infections; Nursing Care; Nursing Process; Standardized Nursing Terminology; Classification. 


\section{INTRODUCTION}

In January 2020, the World Health Organization (WHO) declared a global health emergency based on the increasing rates of notification of cases of an infectious disease caused by a new coronavirus (COVID-19) ${ }^{(1-3)}$. Since then, world governments have worked to this day to contain possible devastating effects ${ }^{(3)}$. The most common clinical manifestations are fever, fatigue and dry cough, and more severe symptoms such as myalgia, dyspnea, nausea, vomiting, diarrhea, pneumonia, and respiratory failure, thus requiring, in many cases, the need for critical support, either in Intensive Care Units (ICU), emergency units, and critical care sectors ${ }^{(1)}$.

As the COVID-19 pandemic spread around the world, healthcare professionals faced an increase in severely ill patients, which generated greater demands for critical support care. Thus, nurses, when providing care to this clientele, can use the Nursing Process (NP), a daily instrument of professional practice that allows assistance in nursing team work organization, contributing to the reduction of signs of complications during critical treatment, as well as giving rise to the identification of priority needs and the development of individualized, humane, irreproachable, and safe care ${ }^{(4)}$.

One of the strategies to support nurses in the best use of NP are the terminological subsets of the International Classification for Nursing Practice (ICNP ${ }^{\circledR}$ ). These consist of nursing diagnoses, results, and interventions, directed to specific groups of people. This ICNP ${ }^{\circledR}$ is a standardized language that represents nursing practice in the world and promotes the appropriate use of NP, expressing itself in competent collection, storage, and analysis of nursing data, resulting in the recognition of the profession and the reality of people's lives ${ }^{(5-6)}$.

In view of the advantages arising from the development of a terminological subset, its construction and dissemination is increasingly present on the world and Brazilian scenes. So far, ten terminological subsets ${ }^{(5)}$ have been published by the International Nurses Council (ICN). However, none in the context of COVID-19, which warrants the present study. Therefore, the study aims to develop and validate a terminological subset of the International Classification for Nursing Practice (ICNP ${ }^{\circledR}$ ) for COVID-19 patients in critical care.

\section{METHOD}

\section{Study Type}

This is a methodological study based on the Brazilian method for the creation of ICNP ${ }^{\circledR}$ terminological subsets, carried out from June to September 2020 and divided into five steps: 1) Integrative literature review to identify terms; 2) Mapping of the terms identified in the review with the ICNP ${ }^{\circledR} 7$-Axis Model; 3) Elaboration of the nursing diagnoses statements, results, and interventions, and construction of diagnoses operational definitions; 4) Validation of nursing diagnoses, results, and interventions by specialist nurses using the Delphi technique; and 5) Organization and structuring of the ICNP ${ }^{\circledR}$ terminology subset for the COVID-19 patient in critical condition, based on the theoretical model by Wanda de Aguiar Horta.

\section{STUDY PROTOCOL}

For the completion of the first step, the extraction of terms, an integrative literature review was carried out looking for studies that addressed the practice of critical care in COVID-19 released between December 2019 and May 2020. The databases used were Latin-American and Caribbean System on Health Sciences Information (LILACS) and the Medical Literature Analysis and Retrieval System Online (MEDLINE/PubMed), with the adoption of the descriptors (Mesh): "coronavirus infections" and "ritical care", associated by the Boolean operator AND. The following inclusion criteria were used: original studies published on the subject proposed, in the Spanish, Portuguese and English languages, available in full for reading, which addressed the critical care subject in COVID-19 in adult patients. As exclusion criteria, works presented in congresses, dissertations, monographs, theses, letters to the editor, reflection studies, literature review, and reports of experiences.

The publications underwent a process of removal of sections with low potential for relevant terms, such as titles, authors, information about the authors, abstracts, footnotes, methodology, references, and acknowledgments. After these extractions, the essential content was grouped into a single file in Word ${ }^{\circledR}$ format, which was converted to a Portable Document Format (PDF).

Then, the terms were extracted using the computational tool PorOnto, which processes information using large-scale ontologies, being commonly used in the health area due to its knowledge complexity ${ }^{(7)}$, resulting in a list of terms organized in order of occurrence, arranged in an Excel ${ }^{\circledR}$ spreadsheet. As PorOnto is a tool for building ontologies from texts in Portuguese, articles in other languages have been translated by specialized professionals.

Among the extracted terms, nouns, adjectives, and verbs were used based on the frequency of appearance and relationship with the theme of the study. Subsequently, the selected terms were normalized as to the standardization regarding gender, number and degree, as well as verbal inflections, to identify and remove repetitions, being compared at all times to reduce the error rate. In addition, terms related to medical procedures, pathological processes, and medications were identified and excluded ${ }^{(8)}$. Then, the normalized terms were subjected to the mapping technique, which allowed the crossing with the terms according to the ICNP $^{\circledR}$ 7-Axis Model, version 2019, using the software Microsoft Office Access ${ }^{\circledR} 2010$ to identify constant and non-constant terms in this terminology, with the ISO 1230: 2016 prerogatives being used ${ }^{(9)}$.

Based on the terms identified and mapped, nursing diagnoses statements and results and interventions were constructed, according to the ICNP ${ }^{\circledR} 7$-Axis Model, version 
2019, the specialized nursing terminology for clinical practice to COVID-19 and ISO 18.104: 2014(10).

For the construction of the diagnoses statements, a term from the "Focus" Axis and a term from the "Judgment" Axis, from a single descriptor equivalent to Focus and Judgment, were included; or from just one Clinical Finding that can represent an altered state, an altered function, or even a change in behavior. The interventions statements construction was accomplished with the combination of terms from the specialized nursing terminology for the clinical practice for COVID-19, following the ISO 18104: 2014 standard, which provides that in every nursing intervention there shall be a descriptor for the action to be carried out (as a rule in $\mathrm{ICNP}^{\circledR}$, a term from the "Action" Axis of the 7-Axis Model) and at least one descriptor related to the target of that action, which can be a term from any other axis, except the "Judgment" axis.

Operational definitions were constructed for nursing diagnoses, using $\mathrm{ICNP}^{\circledR}$, scientific articles, and Portugueselanguage and technical health terms dictionaries, to facilitate validation by expert nurses. The construction of the operational definitions took place according to the following steps recommended in the literature $\left.{ }^{(11)}: 1\right)$ development of a preliminary definition; 2) literature review; 3) development or identification of specific characteristics; 4) mapping of the concept meaning; and 5) affirmation of the operational definition. The fourth step was the content validation by specialist nurses. For that purpose, specialist nurses from Lattes Platform of the National Council for Scientific and Technological Development (CNPq) were sought.

\section{POpulation}

For the selection of nurses, the following inclusion criteria were used: being a nurse, having at least one year of clinical experience in the area of intensive care and/or infectious diseases, and having at least the Master's Degree. To calculate the number of specialists, the following formula was used: $n=Z^{2} 1-\alpha / 2$. p. $(1-p) / e 2$, where " $Z^{2}$ $1-\alpha / 2$ " = confidence level adopted; " $\mathrm{p}$ " = expected proportion of specialists; and " $\mathrm{e}$ " = difference of acceptable proportion in relation to what would be expected ${ }^{(12)}$. The $95 \%$ confidence level was adopted $\left(Z^{2} 1-\alpha / 2=1.96\right)$, with an expected proportion of $85 \%$ of specialists and a sampling error of $15 \%$, resulting in an ideal sample of 22 specialists $(n=1.96$; $0.85 ; 0.15 / 0.152=22)$.

Taking the difficulty in obtaining responses from specialists into account, 35 specialists were invited, with 25 giving an answer, to whom the Free and Informed Consent Form was sent. Following this step, the link to the electronic form to be filled out was sent, which had information on professional characterization, a list of the diagnoses statements, nursing results and interventions according to basic human needs and COVID-19.

The instrument was sent for item-by-item assessment, and each specialist nurse chose to maintain, insert, change, or delete items, in addition to making a general assessment. Stability in the responses was defined when there was agreement by at least $70 \%$ of the participants. It was proposed that each round would last up to 30 days, including the deadline for analysis and feedback from the group of nurses and the 10-day limit for the return by the main researchers with a new version of the statements and the beginning of the next round. Each nurse provided their answers and analysis in a spreadsheet using the software Excel ${ }^{\circledR}$. The result of the previous round was informed to the group in the evaluation of the new version, which included the proposed changes ${ }^{(13)}$.

\section{DATA ANALYSIS AND TREATMENT}

In the instrument for validating nursing diagnoses, results, and interventions, the specialist nurses showed they agreed by marking with an " $x$ " on a "Likert-like" scale containing: Not pertinent; Slightly pertinent; Very pertinent; Extremely pertinent. In addition, they filled out suggestions for writing the nursing diagnosis/result and intervention regarding their use in clinical practice. The specialists had more than 10 years of professional experience in the area of intensive care $(64.28 \%)$, titles of specialists (54\%), and master's degree (55\%).

To assess the degree of agreement among specialists, the Content Validity Index (CVI) was used, determined by the sum of the concordances of items " 3 " and " 4 ". The CVI is defined in the formula: CVI $=\sum$ answers " 3 " and " 4 " $/ \sum$ answers. In the result of the validation, the cut-off point $C V I \geq 0.80$ was taken into account for the consensus of the diagnoses statements and the nursing results and interventions.

In the final step of the subset, the list of nursing diagnoses and results, and interventions was organized according to the concepts of the Model proposed by Wanda de Aguiar Horta for Basic Human Needs, which are psychobiological, psychosocial, and psycho-spiritual, as it is understood that the theoretical model is an integral part of the documentation of importance to nursing, as well as to the organization, and presentation of the subset ${ }^{(14)}$.

\section{ETHICAL ASPECTS}

This study was approved by the Research Ethics Committee, under Opinion No. 4.099.646, approved on June 19,2020, in accordance with Resolution 466/12, of the National Health Council.

\section{RESULTS}

Three productions were found in LILACS and 188 in MEDLINE. Of the total of 191 productions, two from LILACS were excluded because they were institutional protocols; thus, 189 articles were selected for reading of titles and abstracts. Of these, 67 were excluded for not meeting the inclusion criteria, with 122 articles remaining for the integrative review.

A total of 32,987 terms were extracted from the selected publications, and subjected to the process of exclusion of repetitions, normalization, and standardization according to $\mathrm{ICNP}^{\circledR} 2019$ and, at the end, there were 483 terms. The terms mapping identified 376 constant and 
Chart 1 - Distribution of ICNP ${ }^{\circledR}$ diagnoses statements and results organized according to Psychobiological Needs, in COVID-19 patients in critical condition - Natal, RN, Brazil, 2020.

\section{Psychobiological Needs}

Oxygenation: Cough/Cough, Improved; Dyspnea/Dyspnea, Improved; Respiratory Rate, Altered/Respiratory Rate, Improved; Breathing, Impaired/ Breathing, Effective; Gas Exchange, Impaired/Gas Exchange, Effective; Sputum, Present/Sputum, Absent; Respiratory System Process, Impaired/ Respiratory System Process, Positive; Ventilation, Spontaneous, Impaired/ Ventilation, Spontaneous, Effective; Aspiration Risk/Absent Aspiration Risk; Response to Ventilation Weaning, Dysfunctional/Response to Ventilation Weaning, Effective; Ventilation Weaning, Impaired/Ventilation Weaning, Effective; Airway Cleaning, Impaired/Airway Cleaning, Improved; Mechanical Ventilation Patient Care Regimen, Impaired/Mechanical Ventilation Patient Care Regimen, Improved

Hydration: Hypovolemia/Hypovolemia, Absent; Fluids Regimen, Impaired/Fluids Regimen, Improved

Nutrition: Food Intake, Insufficient/Food Intake, Improved; Food, by itself, Impaired/Food, by itself, Improved; Response to Enteral Nutrition, Impaired/Response to Enteral Nutrition, Effective

Elimination: Urinary Frequency, Decreased/Urinary Frequency, Improved; Urinary System Function, Impaired/Urinary System Function, Improved; Renal Function, Impaired/Renal Function, Improved; Urinary Tract Infection/Urinary Tract Infection, Absent; Urinary Retention/Urinary Condition, Effective; Constipation Risk/Constipation Risk, Absent; Constipation/Constipation, Absent; Diarrhea/Diarrhea, Absent; Nausea/Nausea, Absent; Vomiting/Vomiting, Absent

Sleep and Rest: Sleep, Impaired/Sleep, Improved; Fatigue/Fatigue, Absent

Exercise and Physical Activities: Activity Intolerance/Activity Tolerance; Mobility in bed, Impaired/Mobility in bed, Improved

Cutaneous-mucosal Integrity: Tissue/skin integrity, Impaired/Tissue/skin integrity; Risk of Pressure Ulcer (Injury)/Risk of Pressure Ulcer (Injury), Absent; Oral (or Buccal) Mucous Membrane, Impaired/Oral (or Buccal) Membrane, Improved; Risk of Corneal Injury/Risk of Corneal Injury, Absent

Physical Integrity: Risk of Infection/Risk of Infection, Absent; Risk of Falls/Risk of Falls, Absent

Thermal Regulation: Hyperthermia/Body Temperature, within Normal Limits

Hormonal Regulation: Blood Glucose Level, Altered/Blood Glucose Level, at Normal Limits

Neurological Regulation: Coma/Coma, Absent; Agitation/Agitation, Absent

Electrolytic Regulation: Electrolyte Imbalance/Electrolyte Balance

Vascular Regulation: Risk of Septic Shock/Risk of Septic Shock, Absent; Septic Shock/Septic Shock, Absent; Fluid Volume, Impaired/Fluid Volume, Effective; Risk of Deep Venous Thrombosis/Risk of Deep Venous Thrombosis, Absent; Cardiac Process, Impaired/Cardiac Process, Improved; Arrhythmia/Arrhythmia, Absent; Edema/Edema, Absent

Olfactory and Taste Perception: Smell, Impaired/Sense of Smell, Effective; Taste, Impaired/Sense of Taste, Effective

Chart 2 - Distribution of ICNP ${ }^{\circledR}$ diagnoses statements and results organized according to Psychosocial and Psycho-spiritual Needs, in COVID-19 patients in critical condition - Natal, RN, Brazil, 2020.

Psychosocial Needs and Psycho-spiritual Needs

Safety: Anxiety/Anxiety, Reduced; Fear of Death/Fear of Death, Absent

Love: Family Support, Negative/Family Support, Positive

Communication: Family Communication, Impaired/Family Communication, Adequate

Learning (health education): Lack of Knowledge about IIIness/Knowledge about Illness; Lack of Knowledge about Health Status/Knowledge about Health Status; Lack of Knowledge about Therapeutic Regimen/Knowledge about Therapeutic Regimen

Gregariousness: Family Process, Interrupted/Family Process, Improved

Orientation in Time and Space: Disorientation/Orientation

Religious or Theological: Distress/Distress, Improved

107 non-constant terms in $\mathrm{ICNP}^{\circledR}$. The constant terms arrangement according to the $\mathrm{ICNP}^{\circledR}$ 7-Axis Model resulted in: 258 terms on the focus axis; 18 on the judgment axis; 32 on the means axis; 18 on the action axis; 09 on the time axis; 39 on the location axis; and two on the client axis.

Of the 73 nursing diagnoses elaborated, 62 reached a CVI $\geq 0.80$, therefore being validated, as shown in Charts 1 and 2. The non-validated diagnoses were: "Tobacco use",
"Fainting", "Chest pain", "Intestinal incontinence", "Urinary incontinence", "Urge urinary incontinence", "Chronic pain", "Ability to get dressed and undressed", "Caregiver stress risk", "Lack of social support", and "Shame". Regarding the specialists' assessment of the applicability of nursing interventions, only three interventions for the needs of Smell and Taste Perception did not reach a CVI above 0.8 , with the remaining interventions being left, as shown in Charts 3 and 4 . 
Chart 3 - Distribution of nursing diagnoses statements organized according to Psychobiological Needs, in COVID-19 patients in critical condition - Natal, RN, Brazil, 2020.

Safety: Relieve Anxiety; Manage Anxiety; Obtain Anxiety Data; Manage Coping Process, Impaired; Obtain Data on Fear of Death; Reassure the Patient; Assess Attitude Towards Health Condition

Love: Support Family Coping Process; Promote Family Support; Provide (Promote, Give) Emotional Support

Communication: Support Family Coping Process; Promote Family Support; Provide (Promote, Give) Emotional Support; Promote Communication with the Family by Telephone; Listening to the Patient; Strengthening Communication with the Family

Learning (health education): Instruct the patient about the disease; Instruct the Patient on Health Status; Instruct on Therapeutic Regimen; Obtain Knowledge Data on Therapeutic Regimen; Obtain Data on Attitude towards the Therapeutic Regimen; Reinforce Communication

Gregariousness: Promote Family Process, Effective; Support Family Coping Process; Provide Family Support (Promote, Give) Emotional Support; Promote Communication with the Family by Telephone; Listen to the Patient; Strengthen Communication with the Family

Orientation in Time and Space: Promote Cognitive Activity; Monitor Neurological Condition; Obtain Data on Neurological Condition; Obtain Data on Consciousness (Cognition); Get Data on Drug Side Effects

Religious or Theological: Obtain Data on Spiritual Condition; Obtain Data on Spiritual Beliefs; Promote Spiritual Support; Provide (Promote, Give) Privacy for Spiritual Behavior; Advise on Spiritual Anguish; Promote Hope; Promote Coping, Effective

Chart 4 - Distribution of nursing diagnoses statements organized according to Psychosocial and Psycho-spiritual Needs, in COVID-19 patients in critical condition - Natal, RN, Brazil, 2020.

\section{Nursing Interventions}

Oxygenation: Raise Head and Chest; Encourage Cough; Monitor Respiratory Condition; Assess Presence of Expectoration; Prevent Aspiration; Monitor Blood Oxygen Saturation Using Pulse Oximeter; Auscultate Lungs; Measure (or Check) Respiratory Rate; Manage Anxiety; Assess Aspiration Risk; Implement Care with Oxygen Therapy; Implement Comfort Care; Measure (or Check) Respiratory Movements; Aspirate Airways; Monitor Respiratory Therapy; Maintain Patent Airways; Obtain Data on Expectoration (or Sputum); Implement Mechanical Ventilator Care; Monitor Response to Ventilation Weaning; Obtain Data on Respiratory Condition; Interpret Result of Arterial Blood Gas; Implement Ventilation Weaning; Monitor Laboratory Results

Nutrition: Monitor Nutrition; Communicate Nutritional Intake, Impaired; Observe Diet Acceptance; Assist Patient in the Diet; Promote Nutritional Condition, Positive; Collaborate with Nutritionist; Monitor Weight; Care with Enteral Tube; Monitor Weight; Manage Enteral Nutrition

Elimination: Assess Genitourinary Condition; Obtain Data on Urinary Condition; Urinary Catheter Care; Register Urinary Frequency; Record Urine Volume; Monitor Blood and Urine Laboratory Results; Monitor Fluid Balance (or Water Balance); Assess Urinary Condition; Collect Urine Sample; Control Urinary Tract Infection; Manage Urinary Catheter; Obtain Data on Urinary Retention; Promote Urinary Elimination, Effective; Fluid Therapy (or Hydration); Prevent Constipation; Promote Physical Mobility; Auscultate the Abdomen; Get Data on Stools; Monitor Nausea; Monitor Vomiting; Manage Hydration; Assist Oral (or Buccal) Care

Sleep and Rest: Get Data on Sleep; Implement Comfort Care; Promote Sleep; Manage Anxiety; Manage Insomnia; Manage Fatigue; Minimize Anxiety; Obtain Fatigue Data; Implement Comfort Care; Manage Stress due to Change

Exercise and Physical Activities: Assist in Mobility; Help with Progress (or Promote) Mobility; Collaborate with Physiotherapist

Cutaneous-mucosal Integrity: Maintain Skin Integrity; Monitor Skin Integrity; Obtain Skin Integrity Data; Pressure Ulcer (Injury) Prevention; Obtain Data on Oral (Buccal) Condition; Promote Oral (or Buccal) Hygiene; Eye Care

Physical Integrity: Monitor Infection Symptoms and Signs; Monitor Vital Signs; Prevent Infection; Monitor Risk of Falls

Thermal Regulation: Measure (or Check) Body Temperature; Record Body Temperature; Monitor Complications

Hormonal Regulation: Manage Blood Glucose; Measure (or Check) Blood Glucose; Promote Nutritional Condition, Positive

Neurological Regulation: Obtain Data on Consciousness (Cognition); Assess Neurological Condition; Manage Sedation; Promote Mechanical Ventilation Patient Care Regimen; Promote Cognitive Activity; Monitor Neurological Condition

Electrolytic Regulation: Monitor Fluid Balance (or Water Balance); Record Urine Volume; Monitor Electrolytes

Vascular Regulation: Prevent Shock; Manage Hemodynamic Condition; Monitor Blood Pressure; Monitor Heart Condition; Monitor Fluid Balance (or Water Balance); Anticoagulant Therapy; Measure (or Check) Heart Rate; Assess Presence of Edema; Obtain Data on Tissue Perfusion, Peripheral; Register Heart Condition; Check for Presence of Arrhythmia; Communicate Cardiac Arrhythmia; Monitor Weight

Olfactory and Taste Perception: Assess the Ability to Perceive Odors; Obtain Data on Food or Fluid Intake Behavior

\section{DISCUSSION}

The purpose of a terminological subset is to identify the priority human needs for nursing care, based on a homogeneous linguistic set, thus providing less intuitive and more scientific assistance. Therefore, its elaboration and use imply a representation of enriching strategies for the management of nursing care, to the point of favoring the decision-making process, assisting the patients in all their complexity ${ }^{(4)}$, especially in the current scenario of COVID-19, when several human needs are affected, from mild symptoms to intense symptoms, such as severe respiratory distress, which can lead to consequent admission to the ICU ${ }^{(15)}$. 
As it is known, the respiratory airways are the main gateway to SARS-CoV-2 since, once the mentioned anchorage takes place, especially in alveolar cells, inflammatory effects are triggered, a fact that critically contributes to damage to the pulmonary tissue, as well as pathophysiological reactions that explain the respiratory difficulty attested by individuals who are assigned nursing diagnoses characterizing the altered breathing pattern ${ }^{(16-18)}$.

Associated with this concatenation, in pulmonary lesions, a study demonstrates that a peculiar dissociation is found involving the severity of hypoxemia at the ventilation mechanism, which indicates the need for some more invasive ventilation method, in this case, Invasive Mechanical Ventilation $(\mathrm{IMV})^{(19)}$. In view of this context, a severe respiratory condition is established, which determines the strong recommendation of good nursing practices to people on IMV, which warrants the provision of targeted diagnoses that are connected to the endotracheal tube, the mechanical ventilator, prevention of bronchoaspiration, and correct ventilation weaning ${ }^{(20)}$.

The phase of weaning from mechanical ventilation support is seen as progressive and subject to failures, which causes the later withdrawal of this support; thus, the development and adoption of preventive measures and shared care with the health team is relevant, which justifies the indication of nursing diagnoses, results and interventions related to this situation ${ }^{(21)}$.

Simultaneously, it is known that critically ill patients, such as patients diagnosed with COVID-19, present high risk of entry of secretions into the respiratory tract (be they gastrointestinal secretions, oropharyngeal secretions, solids or fluids in the tracheobronchial pathways), what constitutes the event called bronchoaspiration. The possible risk of such an event is due to several factors, such as the presence of an endotracheal tube, incoordination between swallowing and breathing, gastroparesis, dysphagia, complex pharmacotherapy and nutritional therapy through tubes ${ }^{(22)}$. That being said, the applicability of accurate diagnoses that are consistent with this risk and of nursing interventions that are continuous in the actions of health professionals is warranted so that they alert and show the importance of careful compliance as an indicator of the best health care provision and favorable progression for the patient ${ }^{(23)}$.

In the critically ill individual who needs intensive care, such as the use of IMV, organic instability leads to physical phenomena that are intertwined in the hemodynamic context, which refers to the need for "Vascular regulation". Studies show that because they become hemodynamically unstable, these patients need support with vasopressors, with the possibility of certain changes in cardiac function patterns, as well as fluid restriction to limit the development of pulmonary edema, and still have some degree of vasodilation, which can be amplified by sedative drugs during mechanical ventilation ${ }^{(24-25)}$.

Thus, it is appropriate to insert diagnoses that recommend such changes to position the participation of nurses in search for the establishment of possible interventions to their performance and thereby contribute to the gradual patient's recovery. The patient-centered care provided by the nurse shall be effective, attentive and proactive, so that any deterioration or change can be immediately identified and receive treatment, as this care includes the ability to deal with unpredictable and unexpected events in the face of the new scenario of COVID-19(26).

Still regarding the reactions triggered by the SARS$\mathrm{CoV}-2$ infection in the need for "Vascular regulation", nursing diagnoses directed to the infection and its repercussions on the individual were validated, given that the inflammation is unquestionably a critical process in affected patients. Despite the effort of the immune system in trying to contain the infection, this is often not feasible, as there is an excessive number of mediators in the inflammatory process ${ }^{(27)}$.

A study shows that great efforts are being made to identify the specific clinical characteristics of critically infected patients, which mediate the associated pathogenesis, including vascular dysfunction, thrombosis, unregulated inflammation and severe respiratory complications. Recently, COVID-19 has been closely related to sepsis, which suggests that most deaths in intensive care units for infected patients are produced by viral sepsis. Understanding this pathophysiology, the current clinical need to intensively improve care and therapies applied to critically ill patients is of utmost importance ${ }^{(28)}$.

Thus, since the unfolding of other problems emerges, Human Needs, such as "Hormonal Regulation", "Electrolytic Regulation", "Hydration", "Smell and Taste Perception", are affected, which led to the construction and validation of relevant nursing diagnoses and interventions due to the magnitude of these needs to the human being.

The nursing assessment of the "Nutrition" and "Elimination" needs were also considered to the point of reflecting that the early management of the care of patients with COVID-19 should be integrated into the general therapeutic strategy. The literature points out that severe respiratory infections induce inflammatory syndrome and hypercatabolism, with increased energy expenditure linked to ventilation work, which in its turn is responsible for the increase in energy and protein needs. Moreover, it can be reduced by factors such as anorexia secondary to infection, dyspnea, dysosmia, dysgeusia, stress, confinement, and organizational problems that limit attendance at meals, thus contributing to the high risk of malnutrition ${ }^{(29)}$.

With regard to the need for "Elimination", reports indicate that critically ill patients with SARS-CoV-2 infection, especially those with underlying comorbidities, had acute kidney injury, being associated with high mortality rates in this scenario, especially when renal replacement therapy is required ${ }^{(30)}$. Thus, it is clear that patients affected by COVID-19 in critical condition go through numerous problems during their hospitalization period that affect other needs, such as "Sleep and rest", "Cutaneous-mucosal integrity", "Thermal regulation" and "Neurological Regulation".

When considering a patient with SARS-CoV-2 with medium to severe level of impairment, it is very likely that he/she will not be able to develop simple actions, such as minimal routine efforts and self-care habits, nor make 
the most significant decisions applicable to the situation experienced at that moment. Therefore, the development of nursing diagnoses, results and interventions related to "Psychosocial Needs" and "Psycho-spiritual Needs" is warranted.

In the fields of needs such as "Communication", "Learning (health education)", "Orientation in time and space”, "Gregariousness", "Love" and "Safety", they were contemplated with a set of nursing diagnoses and interventions focusing on the holistic approach present in nursing care and on the value of its complexity. As for "Psycho-spiritual needs" in the field "Religious or theological", they are affected as COVID-19 presented unprecedented health challenges in all strata of society. Thus, the balanced spiritual and religious status may be able to promote calm and tranquility, improve physical and mental health, and contribute to healthier behaviors during hospitalization in intensive care.

Consequently, the validation of this subset can indicate contributions to the nurse who provides care in critical care settings, since it promotes care based on the psychobiological, psychosocial, and psycho-spiritual needs affected by COVID-19. This way, performance guided by elements validated by front-line health care workers strengthens such use and expands the possibility of clinical judgment and the insertion of new elements, revealing $\mathrm{ICNP}^{\circledR}$ as an information technology that is in full expansion of its structural language. Furthermore, the theoretical model allowed the characterization of such statements and confirmed that the use of models can direct scientific nursing practice, based on its multiple theoretical nuances.

Finally, as a limitation of this study, the validated subset needs to be subjected to clinical validation to improve its prediction and specificity, which requires further studies.

\section{CONCLUSION}

The $\mathrm{ICNP}^{\circledR}$ terminological subset developed showed statements of nursing diagnoses, results, and interventions that were validated by specialist and acting nurses, and that, therefore, are relevant to the nurse's clinic in the critical care setting associated with Covid-19. Thus, the subset contributes to clinical reasoning and decisionmaking that strengthen safe and holistic care through the application of specialized language terminology and the look of the theoretical model used, in addition to allowing the implementation of the nursing process using everyday phenomena.

\section{RESUMO}

Objetivo: Elaborar e validar um subconjunto terminológico da Classificação Internacional para a Prática de Enfermagem a pessoas com COVID-19 em cuidados críticos. Método: Estudo metodológico, que seguiu as orientações do método brasileiro, tendo como modelo teórico as Necessidades Humanas Básicas. A validação de conteúdo foi realizada por 25 enfermeiros especialistas por meio da técnica Delphi. Resultados: Foram elaborados 73 diagnósticos e seus respectivos resultados de enfermagem. Destes, 62 enunciados apresentaram Índice de Validade de Conteúdo $\geq 0,80$, sendo a necessidade de oxigenação a com maior número de enunciados. Das 210 intervenções de enfermagem elaboradas, e após sugestões dos especialistas, 150 intervenções alcançaram índice $\geq 0,80$ e compuseram o subconjunto terminológico. Conclusão: $\mathrm{O}$ subconjunto terminológico desenvolvido evidenciou enunciados que foram validados pelos enfermeiros especialistas e que, dessa forma, configuram-se relevantes para a clínica do enfermeiro no cenário de cuidados críticos associados à Covid-19.

\section{DESCRITORES}

Infecções por Coronavírus; Cuidados de Enfermagem; Processo de Enfermagem; Terminologia Padronizada em Enfermagem; Classificação.

\section{RESUMEN}

Objetivo: Elaborar y validar un subconjunto terminológico de la Clasificación Internacional para Práctica de Enfermería (CIPE $\left.{ }^{\circledR}\right)$ a personas con COVID-19 en cuidados críticos. Método: Estudio metodológico, que siguió las orientaciones del método brasileño, y tuvo como modelo teórico las Necesidades Humanas Básicas. La validez de contenido fue realizada por 25 enfermeros expertos por medio de la técnica Delphi. Resultados: Fueron elaborados 73 diagnósticos y sus respectivos resultados de enfermería. De esos, 62 enunciados presentaron Índice de Validez de Contenido $\geq 0,80$, siendo la necesidad de oxigenación con mayor número de enunciados. De las 210 intervenciones de enfermería elaboradas, y, tras sugerencias de los expertos, 150 intervenciones alcanzaron índice $\geq 0,80$ y compusieron el subconjunto terminológico. Conclusión: El subconjunto terminológico desarrollado mostró enunciados que fueron validados por los enfermeros expertos, y que, de esa manera, demuestran ser relevantes para la clínica del enfermero en el escenario de cuidados críticos asociados a la COVID-19.

\section{DESCRIPTORES}

Infecciones por Coronavirus; Atención de Enfermería; Proceso de Enfermería; Terminología Normalizada de Enfermería; Classificación.

\section{REFERENCES}

1. Dong X, Cao Y, Lu X, Zhang J, Du H, Yan Y, et al. Eleven faces of coronavirus disease 2019. Allergy. 2020;75(7):1699-709. doi: https:// doi.org/10.1111/all.14289

2. Velavan TP, Meyer CG. The COVID-19 epidemic. Trop Med Int Health. 2020;25(3):278-80. doi: https://doi.org/10.1111/tmi.13383

3. Clark A, Jit M, Warren-Gash C, Guthrie B, Wang HHX, Mercer SW, et al. Global, regional, and national estimates of the population at increased risk of severe COVID-19 due to underlying health conditions in 2020: a modelling study. Lancet Glob Health. 2020;8(8):e1003-e1017. doi: https://doi.org/10.1016/ S2214-109X(20)30264-3 
4. Souza Neto VL, Silva RAR, Silva CC, Negreiros RV, Rocha CCT, Nóbrega MML. Proposal of nursing care plan in people hospitalized with AIDS. Rev Esc Enferm USP. 2017;51:e03204. doi: http://dx.doi.org/10.1590/S1980-220X2016027203204

5. Menezes HF, Camacho ACLF, Nóbrega MML, Fuly PSC, Fernandes SF, Silva RAR. Paths taken by Brazilian Nursing for the development of terminological subsets. Rev Latino Am Enfermagem. 2020;28:e3270. doi: http://dx.doi.org/10.1590/1518-8345.3132.3270

6. Passinho RS, Primo CC, Fioresi M, Nóbrega MML, Brandão MAG, Romero WG. Elaboration and validation of an ICNP ${ }^{\circledR}$ terminology subset for patients with acute myocardial infarction. Rev Esc Enferm USP. 2019;53:e03442. doi: http://dx.doi.org/10.1590/S1980$220 \times 2018000603442$

7. Zahra FM, Carvalho DR, Malucelli A. Poronto: tool for semi-automatic ontology construction in portuguese. J Health Inform. 2013;5(2):52-9.

8. Menezes HF, Lima FR, Camacho ACLF, Dantas JC, Ferreira LB, Silva RAR. Specialized nursing terminology for the clinical practice directed at Covid-19. Texto Contexto Enferm. 2020;29: e20200171. doi: https://doi.org/10.1590/1980-265X-TCE-2020-0171

9. International Organization for Standardization. ISO 12300: health informatics: principles of mapping between terminological systems. Geneva: ISO; 2016.

10. International Organization for Standardization. ISO 18104: health informatics: categorial structures for representation of nursing diagnoses and nursing actions in terminological systems. Geneva: ISO; 2014.

11. Lenz E. Basic principles of measurement: operationalizing nursing concepts. In: Waltz CF, Strickland OL, Lenz E. Measurement in nursing and health research. $5^{\text {th }}$ ed. New York: Springer; 2017.

12. Lopes MV, Silva VM, Araujo TL. Methods for establishing the accuracy of clinical indicators in predicting nursing diagnoses. Int J Nurs Knowl. 2012;23(3):134-9. doi: 10.1111/j.2047-3095.2012.01213.x

13. Scarparo AF, Laus AM, Azevedo ALCS, Freitas MRI, Gabriel CS, Chaves LDP. Reflexões sobre o uso da técnica Delphi em pesquisas na enfermagem. Rev Rene. 2012;13(1):242-51. doi: https://doi.org/10.15253/rev\%20rene.v13i1.3803

14. Horta WA. Processo de enfermagem. Rio de Janeiro: Guanabara Koogan; 2011.

15. Zhu N, Zhang D, Wang W. A novel coronavirus from patients with pneumonia in China, 2019. N Engl J Med. 2020;382:727-33. doi: 10.1056/NEJMoa2001017

16. Xu H, Zhong L, Deng J. High expression of ACE2 receptor of 2019-nCoV on the epithelial cells of oral mucosa. Int J Oral Sci. 2020;12:1-5. doi: https://doi.org/10.1038/s41368-020-0074-x

17. Ou X, Liu Y, Lei X. Characterization of spike glycoprotein of SARS-CoV-2 on virus entry and its immune cross-reactivity with SARS-CoV. Nat Commun. 2020;11:1620. doi: https://doi.org/10.1038/s41467-020-15562-9

18. Schouten LRA, Helmerhorst HJF, Wagenaar GTM. Age-dependent changes in the pulmonary renin-angiotensin system are associated with severity of lung injury in a model of acute lung injury in rats. Crit Care Med. 2016;44:e1226-35. doi: 10.1097/ CCM.0000000000002008

19. Gattinoni L, Coppola S, Cressoni M. Covid-19 does not lead to a "typical" acute respiratory distress syndrome. Am J Respir Crit Care Med. 2020;201(10):1299-300. doi: 10.1164/rccm.202003-0817LE

20. Santos C, Nascimento ERP, Hermida PMV, Silva TG, Galetto SGS, Silva NJC, Salum NC. Good nursing practices towards patients on invasive mechanical ventilation in hospital emergency. Esc Anna Nery. 2020;24(2):e20190300. doi: http://dx.doi.org/10.1590/21779465-ean-2019-0300

21. Silva LCR, Tonelli IS, Oliveira RCC, Lemos PL, Matos SS, Chianca TCM. Clinical study of dysfunctional ventilatory weaning response in critically ill patients. Rev Latino Am Enfermagem. 2020;28:e3334. doi: http://dx.doi.org/10.1590/1518-8345.3522.3334

22. Bispo MM, Dantas ALM, Silva PKA, Fernandes MICD, Tinôco JDS, Lira ALBC. The nursing diagnosis of aspiration risk in critical patients. Esc Anna Nery 2016; 20(2):357-62. doi: 10.5935/1414-8145.20160049

23. Cruz JRM, Martins MDS. Pneumonia associated with invasive mechanical ventilation: nursing care. Rev Enf Ref. 2019; serlV(20):87-96. doi: http://dx.doi.org/10.12707/RIV18035

24. Michard F, Malbrain ML, Martin GS, Fumeaux T, Lobo S, Gonzalez F, et al. Haemodynamic monitoring and management in COVID-19 intensive care patients: an International survey. Anaesth Crit Care Pain Med. 2020;39(5):563-69. doi: https://doi.org/10.1016/j. accpm.2020.08.001

25. Bendjelid K, Muller L. Haemodynamic monitoring of COVID-19 patients: classical methods and new paradigms. Anaesth Crit Care Pain Med. 2020;39(5):551-2. doi: https://doi.org/10.1016/j.accpm.2020.09.001

26. Carter C, Notter J. COVID-19 disease: a critical care perspective. Clin Integrat Care. 2020;1:100003. doi: 10.1016/j.intcar.2020.100003

27. Zhou F, Yu T, Du R. Clinical course and risk factors for mortality of adult inpatients with COVID-19 in Wuhan, China: a retrospective cohort study. Lancet. 2020;395:1054-62. doi: https://doi.org/10.1016/S0140-6736(20)30566-3

28. Beltrán-García J, Osca-Verdegal R, Pallardó FV, Ferreres J, Rodríguez M, Mulet S, et al. Sepsis and Coronavirus Disease 2019: common features and anti-inflammatory therapeutic approaches. Crit Care Med. 2020;18:10.1097/CCM.0000000000004625. doi: 10.1097/ CCM.0000000000004625

29. Thibault R, Seguin P, Tamion F, Pichard C, Singer P. Nutrition of the COVID-19 patient in the intensive care unit (ICU): a practical guidance. Crit Care. 2020;24(1):447. doi: 10.1186/s13054-020-03159-Z

30. Gabarre P, Dumas G, Dupont T, Darmon M, Azoulay E, Zafrani L. Acute kidney injury in critically ill patients with COVID-19. Intensive Care Med. 2020;46(7):1339-48. doi: 10.1007/s00134-020-06153-9 